\title{
Relationship between physical attributes and heat stress in dairy cattle from different genetic groups
}

\author{
Evelyn Priscila München Alfonzo ${ }^{1,4}$ - Marcos Vinicius Gualberto Barbosa da Silva ${ }^{3}$. \\ Darlene dos Santos Daltro ${ }^{1}$ • Marcelo Tempel Stumpf ${ }^{1,5}$ • Vanessa Calderaro Dalcin ${ }^{1}$. \\ Giovani Kolling ${ }^{1} \cdot$ Vivian Fischer $^{1}$ - Concepta Margaret McManus ${ }^{1,2}$
}

Received: 24 May 2014 / Revised: 30 April 2015 / Accepted: 25 May 2015 / Published online: 11 June 2015

(C) ISB 2015

\begin{abstract}
Dairy cattle raised under harsh conditions have to adapt and prevent heat stress. The aim of this study was to evaluate physical characteristics and their association with heat tolerance in different genetic groups of dairy cattle. Thickness of the skin and coat, length and number of hairs, body measurements, as well as physiological parameters and body temperatures by infrared thermography were determined in 19 Holstein and 19 Girolando ( $1 / 2$ and $3 / 4$ Holstein) cows. The Holstein cattle were less tolerant to heat stress than Girolando (GH50 and GH75 Holstein), because of the difficulty in dissipating heat due to the larger body size, as well as thicker and longer hairs. The correlations between physical characteristics, physiological parameters, and thermographic measurements prove to be inconsistent among genetic groups and therefore are not predictive of heat tolerance, while the regressions of morphometric characteristics on physiological and thermographic measures were not significant. Thus, the physical characteristics were not good predictors of physiological indices and thermographic temperature and so should not be used.
\end{abstract}

Evelyn Priscila München Alfonzo

evelynpma@hotmail.com

1 Animal Production Department, Federal University of Rio Grande do Sul, Porto Alegre, RS, Brazil

2 Faculty of Agriculture and Veterinary Medicine, University of Brasília, Brasília, DF, Brazil

3 Embrapa Dairy Cattle, Juiz de Fora, MG, Brazil

4 Postgraduate Program in Animal Science, Bento Gonçalves Avenue, 7712, 91540-000 Porto Alegre, RS, Brazil

5 Faculty of Agroecology, Federal University of Rio Grande-FURG, São Lourenço do Sul, 15, RS, Brazil
Keywords Tolerance $\cdot$ Thermography $\cdot$ Coat and cows

\section{Introduction}

In recent years, Brazilian milk production has undergone significant changes aiming at increasing productivity through the use of modern technologies, but also respecting the principles of sustainability and animal well-being. The objective of this new model of production is decreasing animal stress caused by the production environment, which is important physiologically and economically, prioritizing production efficiency (Lima et al. 2013).

Dairy cattle raised in tropical climates often suffer from heat stress, due to their high productivity, undergoing physiological and behavioral changes caused by heat stress, where high ambient temperatures, relative humidity, and solar radiation hinder heat dissipation (Silva et al. 2002). In dairy cows, for example, one of the biggest obstacles is to associate highly productive genotypes with those adapted to these hot environments, because the more adapted animals tend to have lower food intake and milk production (Façanha-Morais et al. 2008).

Increase milk production in the tropics may include the use of more productive genotypes, providing an environment more compatible with animal requirements and the use of adapted animals, selecting the most productive (Façanha et al. 2013). Holstein cattle express the peak of their genetic potential when ambient temperatures are between 5 and $18^{\circ} \mathrm{C}$. However, values above this range are frequently found in most regions of Brazil during a great part of the year (Dikmen and Hansen 2009). The high air temperature, especially when combined with high humidity and intense solar radiation, is responsible for the decrease in milk production of cows of medium and high production (Baccari Jr. 2001). 
When animals are outside their thermoneutral zone, reproductive functions, physiological parameters, and performance are negatively affected. The thermoneutral zone varies according to sex, age, breed, and productive state, among others (Tosetto et al. 2014), and for dairy cattle is in the range of 10 to $20^{\circ} \mathrm{C}$ (Rodrigues et al. 2012; Nascimento et al. 2013).

In response to heat stress, animals react with physiological and behavioral changes to try to prevent hyperthermia. In tropical environments, the physical mechanism more efficient is evaporative heat loss, because it does not depend on the temperature difference between the body and atmosphere (Silva 2000). The responses of animals to thermal environment can be estimated through observation of physiological parameters such as rectal temperature (RT) and respiration rate (RR) (Perissinotto et al. 2009).

The prevention of overheating and elevation of body temperature to levels that could compromise the health of the animals under severe heat is possible due to the release of large quantities of metabolic heat (Gebremedhin and $\mathrm{Wu}$ 2002). In this sense, the skin has a great importance in such process, since its function is to generate, absorb, transmit, radiate, conduct, and vaporize heat (Xu et al. 2007).

Several features can be used to evaluate the adaptation of animals to heat, including their physical characteristics (Marai et al. 2007). The capacity of tolerance to intense solar radiation, an important characteristic for animals kept on pasture, is directly related to the presence of an external layer of hair (Silva 2000). According to Silva (1999), animals suitable to be reared outdoors in tropical regions should have light-colored, short, thick, and well-medullated hair on a highly pigmented epidermis. These characteristics favor both convection and evaporation processes on the skin surface, while high levels of melanin in the epidermis protects against ultraviolet radiation.

New technologies such as infrared thermography are a viable alternative in defining the impact of environmental factors on animal production and prevent damage to the health and animal welfare (Paim et al. 2013). It has been considered, at an experimental level, to have a relevant role in animal production as a safe, noninvasive technique that is useful for several analyses such as detection of mastitis (Martins et al. 2013); pain, illness, and injuries (Schaefer et al. 2007; Stewart et al. 2008); as well as methane production (Montanholi et al. 2008). Thermographic measurements do not require direct physical contact with the monitored surface and assessment of the temperature of the animals in their natural environment, providing information on their thermal state without the need for invasive and stressful procedures, such as capture and containment.

The objective of this study was to determine which physical characteristics are better predictors of the effect of heat on different genetic groups of dairy cattle.

\section{Materials and methods}

The experiment was approved by the Ethics Committee on the Use of Animals of the Federal University of Rio Grande do Sul, number 22773/2012, and carried out at the Brazilian Corporation of Agricultural Research (Embrapa), Dairy Cattle Station, Brazil.

Thirty-eight cows were used in a 6-day experiment: 19 Holstein (H100) and 19 Girolando [1/2 Holstein-Gir (GH50, $n=8)$ and $3 / 4$ Holstein-Gir $(\mathrm{GH} 75, n=11)]$. At the start of their respective periods of analysis, Holstein cows presented an average of $249.15 \pm 68.19$ days in milk (DIM) and $14.80 \pm$ $2.59 \mathrm{~L} \mathrm{day}^{-1}$ milk production; GH50 cows presented $95 \pm$ $72.33 \mathrm{DIM}$ and $12.40 \pm 3.42 \mathrm{~L} \mathrm{day}^{-1}$ milk production; and GH75 showed 169.3 \pm 95.85 DIM and 14.62 $\pm 2.95 \mathrm{~L}$ day $^{-1}$ milk production. Data collection for each breed lasted three consecutive days, with experimental procedures being the same for the different breeds. In spite of that, Holstein (H100) and Girolando (GH50+GH75) cows were analyzed in separate locations and periods since they were housed separately in the experimental station. In this manner, it is important to compare animals at the same production level to better elucidate the effects of physical characteristics for heat dissipation without an interaction with milk production levels.

The study consisted of inducing heat stress by exposing cows to a non-shaded environment-with water ad libitum-between morning and evening milkings. During experimental procedures, temperature varied from 21 to $34{ }^{\circ} \mathrm{C}$ (average of $26.61^{\circ} \mathrm{C}$ ) and relative humidity ranged from 56 to $95 \%$ (average of $77.55 \%$ ) for GH75 and GH50. For H100 cows, the same parameters ranged from 22 to $35^{\circ} \mathrm{C}$ (average of $28.3{ }^{\circ} \mathrm{C}$ ) and from 52 to $95 \%$ (average of $76.68 \%$ ), respectively.

H100 cows were housed in a free stall, receiving a total mixed ratio of maize silage and concentrate (59\% corn, $35 \%$ soybean, $3.5 \%$ protein-mineral-vitamin core, $0.5 \%$ mineral salt, $1 \%$ urea, and $1 \%$ bicarbonate); between milkings, cows were conducted to a Brachiaria brizantha pasture. GH50 and GH75 were conducted in Pennisetum purpureum pasture and fed concentrate before each milking (70 \% corn, $25 \%$ soybean, $3.5 \%$ protein-mineral-vitamin core, $0.5 \%$ mineral salt, and $1 \%$ urea) in quantities according to milk production. Animals used belong to Embrapa; thus, housing and feeding techniques were not altered nor established by authors, with the exception of heat stress induction.

At the first day, physical characteristics, physiological parameters, and thermography measures were taken. Physical properties were performed in triplicate at a single moment for each animal and consisted of thickness of skin and coat, number and length of hairs, and body measurements. Skin thickness was performed using a caliper graduated in tenths of millimeters and measured at the scapula (Sscapula and Tscapula), back (Sback and Tback), and flank (Sflank and 
Tflank) regions of the animals. For the number of hairs, samples were collected in the upper part of the central region of the scapula. An area of about $1 \mathrm{~cm}^{2}$ was marked and measured and all the hair from this region collected using adapted pliers. The hair collected was packed in aluminum envelopes for posterior total count and measurement. The hair count (CountHair) was performed by spreading the sample over a white sheet of paper (as the hair was dark) with the aid of tweezers and needles according to Silva (2000). To measure the length of the samples (LengthHair), ten of the longest hairs from each animal were separated and measured with a ruler. Subsequently, the average hair length was calculated according to Silva (2000).

Body measures were obtained with the aid of a graduated tape and a hipometer: height at the withers (withers) measuring the distance between the highest point of the withers to the ground; body length (BodyL) consisted of the distance between the base of the tail and the base of the neck; back length (BackL) measuring the distance between the first lumbar vertebra; and the last, chest girth (Chestgirth), was obtained using the boundaries obtained in the rear part of the shoulders near the armpits.

The physiological parameters monitored included rectal temperature (RT), respiratory rate (RR), heart rate (HR), and panting score (PS). RT was measured using a clinical veterinary thermometer inserted at the rectum wall of the animal at a depth of approximately $30 \mathrm{~cm}$ during $3 \mathrm{~min}$. HR, expressed in number of beats per minute, was measured using a stethoscope and stopwatch for $30 \mathrm{~s}$ and multiplying the result by 2 to obtain this variable in minutes. The RR, expressed in number of breaths per minute, was measured using a stethoscope and stopwatch upon auscultation of respiratory movements for $30 \mathrm{~s}$, and the value obtained was multiplied by 2 to obtain this variable in minutes. The panting score was assigned at the time of collecting physiological data according to Mader et al. (2006) - (Table 1).

An infrared camera (FLIR T300 ${ }^{\circledR}$ System) was used to obtain the thermographic images of different regions of the body of the animals. This type of portable camera converts an object's (in this case, skin surface of dairy cows) naturally emitted radiation at a wavelength of $10-30 \mathrm{~mm}$ into an electrical signal which is then processed into a thermal pattern; the camera can detect $2 \%$ at a thermal sensitivity of $0.1{ }^{\circ} \mathrm{C}$. This procedure was performed right after physiological measurements and before milking, with animals in a shaded environment. A total of six photos were taken in each animal. The thermographic images enabled the collection of temperatures of the regions on the right (RightS) and left (LeftS) flanks of the animal, eye (Eye), lateral right (LatUdder) and posterior (PostUdder) views of the udder, as well as right posterior forelimb (Paw). All IR were taken approximately $1.50 \mathrm{~m}$ from each of the body locations studied, and multiple pictures were taken from the same locations for selecting the picture with the
Table 1 Panting score in dairy cattle

\begin{tabular}{ll}
\hline Score & Description \\
\hline 0 & Normal breathing \\
1 & Slightly increased respiratory rate \\
2 & And/or presence of drool or small amount of saliva \\
3 & Saliva usually present, heavy panting with open mouth \\
4 & Severe panting with her mouth open, tongue protrusion, \\
& excessive salivation, and generally extended neck
\end{tabular}

Source: Mader et al. 2006

best quality in terms of focus and precise location. For each of the locations photographed, a specific shape was considered in order to keep a constant sub-area. Subsequently, QuickReport ${ }^{\circledR} /$ FLIR-Systems software was used for temperature analysis of thermographic images.

The mathematical model for the evaluation of genetic groups regarding physical characteristics was

$\begin{array}{ll}Y_{\mathrm{ij}} & \mu+\text { breed }_{\mathrm{i}}+e_{\mathrm{ij}} \\ Y_{\mathrm{ij}} & \text { Set of dependent variables } \\ \text { Breed }_{\mathrm{i}} & \text { Breed of animals } \\ \mu & \text { Overall mean } \\ e_{\mathrm{ij}} & \text { Random error associated with each observation }\end{array}$

All statistical procedures were performed using SAS for Windows version 9.3 (SAS Institute, Cary, NC, USA). Statistical analysis included analysis of variance (PROC GLM) to determine differences among genetic groups for morphometric characteristics, standardization of values (PROC STAN DARD), variable selection for discriminant analysis (PROC STEPDISC) to generate correlation coefficients between the physical and physiological characteristics in the afternoon when the animals were under heat stress (PROC CORR), regression analysis to determine the effect of morphometric characteristics on physiological parameters and temperatures measured by infrared thermography in the afternoon (PROC REG), discriminant analysis to determine which morphometric characteristics differ between genetic groups (PROC DISC RIM), canonical analysis for the morning and afternoon (PROC CANDISC) measurements, and analysis of key factors for the morning and afternoon (PROC FACTOR) measurements.

\section{Results}

The mean HR, RR, and body temperature (according to RT) varied significantly $(P<0.001)$ between genetic groups (Table 2). The Holstein cows had higher means for RT and RR but lower HR in the morning than GH50 and GH75. No difference was detected for PS for the genetic groups. In the afternoon, RT, RR, and HR were similar for H100 and GH75. 
Table 2 Physiological parameters of the dairy cows from three genetic groups depending on time of day

\begin{tabular}{llllllll}
\hline & \multicolumn{3}{c}{ Morning } & \multicolumn{5}{l}{ Afternoon } \\
\cline { 2 - 3 } \cline { 7 - 8 } \cline { 6 - 7 } & GH50 & GH75 & H100 & & GH50 & GH75 & H100 \\
\hline RT & $38.24^{\mathrm{b}}$ & $37.97 \mathrm{~b}$ & $38.83 \mathrm{a}$ & & $40.03 \mathrm{~b}$ & $40.72 \mathrm{a}$ & $40.84 \mathrm{a}$ \\
RR & $35.50^{\mathrm{c}}$ & $44.66 \mathrm{~b}$ & $50.66 \mathrm{a}$ & & $77.00 \mathrm{~b}$ & $107.60 \mathrm{a}$ & $111.36 \mathrm{a}$ \\
HR & $59.17^{\mathrm{ab}}$ & $62.26 \mathrm{a}$ & $56.84 \mathrm{~b}$ & & $69.16 \mathrm{~b}$ & $89.46 \mathrm{a}$ & $99.22 \mathrm{a}$ \\
PS & $0^{\mathrm{a}}$ & $0 \mathrm{a}$ & $0 \mathrm{a}$ & & $1.04 \mathrm{c}$ & $2.13 \mathrm{~b}$ & $3.03 \mathrm{a}$ \\
\hline
\end{tabular}

Values followed by the same letter in the row and period of day are not significantly different in the test at $5 \%$ probability

GH50 Girolando cows with $50 \%$ Holstein blood, GH75 Girolando cows with $75 \%$ Holstein blood, $R T$ rectal temperature $\left({ }^{\circ} \mathrm{C}\right), R R$ respiratory rate (breaths/min), $H R$ heart rate (beats/min), $P S$ panting score (mov/min)

GH50 presented the lowest values for physiological traits. PS increased as Holstein genotype was more prevalent. Therefore, analyses were performed according to the time of day.

In terms of morphometric measurements, analysis of variance showed that the animals GH50 and GH75 differed statistically from the $\mathrm{H} 100$ animals, having lower means for several physical characteristics: body measurements (wither, BodyL, BackL, Chestgirth), medium hair length, and thickness of coat. Only skin thickness at the scapula and the number of hairs were lower for Holsteins (Table 3).

Table 3 Multivariate analysis of variance (MANOVA) of the physical characteristics of different genetic groups of dairy cattle

\begin{tabular}{llll}
\hline Characteristics & \multicolumn{2}{l}{ Genetic groups } & \\
\cline { 2 - 4 } & GH50 & GH75 & H100 \\
\hline Withers (m) & $1.41 \mathrm{~b}$ & $1.39 \mathrm{~b}$ & $1.43 \mathrm{a}$ \\
BodyL (m) & $1.73 \mathrm{~b}$ & $1.74 \mathrm{~b}$ & $1.87 \mathrm{a}$ \\
BackL (m) & $0.95 \mathrm{~b}$ & $0.94 \mathrm{~b}$ & $1.17 \mathrm{a}$ \\
Chestgirth (m) & $1.88 \mathrm{~b}$ & $1.82 \mathrm{c}$ & $1.97 \mathrm{a}$ \\
Sscapula (cm) & $0.92 \mathrm{a}$ & $0.89 \mathrm{a}$ & $0.69 \mathrm{~b}$ \\
Sback (cm) & $1.24 \mathrm{a}$ & $1.03 \mathrm{~b}$ & $1.07 \mathrm{~b}$ \\
Sflank (cm) & $1.49 \mathrm{a}$ & $1.14 \mathrm{~b}$ & $1.06 \mathrm{~b}$ \\
Tscapula (cm) & $0.16 \mathrm{~b}$ & $0.17 \mathrm{~b}$ & $0.23 \mathrm{a}$ \\
TBack (cm) & $0.23 \mathrm{~b}$ & $0.24 \mathrm{~b}$ & $0.33 \mathrm{a}$ \\
Tflank (cm) & $0.21 \mathrm{~b}$ & $0.23 \mathrm{~b}$ & $0.28 \mathrm{a}$ \\
CountHair & $519.38 \mathrm{a}$ & $501.20 \mathrm{a}$ & $327.47 \mathrm{~b}$ \\
LengthHair (cm) & $0.85 \mathrm{~b}$ & $0.86 \mathrm{~b}$ & $1.34 \mathrm{a}$ \\
\hline
\end{tabular}

Values followed by the same letter in the row and period of day are not significantly different in the test at $5 \%$ probability

Withers height at the withers, BodyL length of the body, BackL back length, Chestgirth chest girth, Sscapula skin thickness of the scapula, Sback skin thickness of the back, Sflank skin thickness of the flank, Tscapula thickness of the scapula, TBack thickness of the back, Tflank thickness of the flank, CountHair the hair count, LenghtHair length of hair
Significant regression equations of morphometric characteristics on physiological parameters and temperatures measured by infrared thermography in the afternoon were not found for the afternoon period, so the physical characteristics were not good at predicting heat tolerance within and between different genetic groups.

Physical characteristics had correlations ranging from low to moderate with the physiological parameters and with the thermograms in the afternoon (Table 4). For GH50, an average negative correlation between BackL and LeftS $(r=-0.43)$ and an average positive correlation between mean and Tflank and $\mathrm{RR}(r=0.45)$ were found. For GH75 in the afternoon, there was a moderate positive correlation between Tscapula and LatUdder temperatures $(r=0.38)$, LengthHair and thermographic temperatures of the Eye, LatUdder and PostUdder $(r=0.46,0.38$ and 0.42 respectively), and moderate and negative between Sback with PostUdder and RT ( $r=-0.41$ and -0.44 , respectively).

The Holstein animals had negative and low correlations between Chestgirth, Sback, and Tflank with Paw temperature ( $r=-0.31,-0.31$, and -0.30 , respectively), and CountHair had a negative moderate correlation with RR and HR ( -0.31 and $-0.31)$ as well as Sback with RR $(-0.33)$ and Paw $(-0.31)$. The average hair length (LengthHair) was correlated positively but moderately with temperature measured in LatUdder $(r=0.34)$.

In general, these correlations were inconsistent between the different genetic groups. For example, correlations between the withers and LeftS ranged from 0.07 to 0.38 , as Paw and Chestgirth correlations ranged from -0.31 to 0.07 and $R R$ with Chestgirth ranged from 0.25 to 0.42 , and so they were not good predictors of performance.

Seven physical characteristics differentiated between genetic groups, as revealed by the high significance in the multivariate test. Chestgirth presented the highest value for partial $R^{2}$, being highly significant for the $F$ test and can be considered the most important variable in differentiating the genotypes used. The height at the withers was also highly significant, but with a partial $R^{2}$ value of 0.224 . The other physical characteristics were considered discriminating because they were significantly correlated, but with a low but significant partial $R^{2}$ and $F$ value (Table 5).

The canonical analysis (Fig. 1) showed that the first canonical variable separated the purebred from crossbred animals, while the second separated GH50 from GH75. Through the canonical distribution of the groups, it was seen that body measurements (withers, BodyL, BackL, and Chestgirth), the thickness of the coat, and average hair length were associated with Holstein cows, while the thickness of the skin (Sscapula, Sback, and Sflank) and the number of hair were associated with Girolando (GH50 and GH75).

For the first canonical correlation, the physical characteristics were different between pure and crossbreds. For the second canonical correlation, there was a difference between 
Table 4 Correlations between physical characteristics, physiological parameters, and infrared temperature

\begin{tabular}{|c|c|c|c|c|c|c|c|c|c|c|}
\hline & Eye & LeftS & RightS & LatUdder & PostUdder & Paw & RT & $\mathrm{RR}$ & HR & $\mathrm{S}$ \\
\hline \multicolumn{11}{|l|}{ GH50 } \\
\hline Withers & -0.15 & -0.38 & -0.09 & -0.05 & 0.06 & -0.02 & -0.01 & -0.28 & -0.28 & -0.36 \\
\hline BodyL & 0.22 & -0.03 & 0.03 & 0.03 & 0.26 & -0.03 & 0.11 & 0.06 & 0.16 & 0.03 \\
\hline BackL & -0.24 & $-0.43 *$ & -0.13 & -0.21 & -0.19 & -0.32 & -0.32 & -0.08 & -0.10 & -0.20 \\
\hline Chestgirth & -0.29 & -0.40 & -0.15 & -0.24 & 0.04 & -0.07 & -0.06 & -0.25 & -0.19 & -0.22 \\
\hline Sscapula & 0.17 & -0.04 & 0.09 & 0.23 & 0.08 & -0.02 & 0.06 & 0.10 & 0.08 & 0.03 \\
\hline Sback & -0.05 & -0.06 & 0.15 & 0.06 & -0.05 & -0.05 & -0.01 & -0.04 & -0.11 & -0.18 \\
\hline Sflank & -0.14 & -0.35 & 0.19 & -0.11 & 0.04 & -0.28 & -0.06 & 0.01 & -0.04 & -0.23 \\
\hline Tscapula & -0.30 & -0.18 & 0.01 & -0.26 & -0.21 & -0.25 & -0.18 & 0.10 & -0.25 & -0.00 \\
\hline Sback & 0.05 & -0.19 & 0.03 & 0.01 & 0.01 & -0.27 & -0.00 & 0.35 & 0.08 & 0.05 \\
\hline Tflank & 0.23 & -0.00 & 0.11 & 0.06 & 0.01 & -0.27 & -0.00 & $0.45^{*}$ & 0.23 & 0.16 \\
\hline CountHair & 0.17 & 0.65 & 0.30 & -0.01 & 0.12 & 0.26 & 0.29 & 0.18 & 0.16 & 0.24 \\
\hline LengthHair & -0.38 & -0.09 & -0.01 & -0.15 & -0.26 & -0.02 & -0.17 & -0.15 & -0.15 & -0.06 \\
\hline \multicolumn{11}{|l|}{ GH75 } \\
\hline Withers & 0.22 & 0.23 & 0.16 & 0.14 & 0.31 & 0.00 & 0.20 & -0.02 & 0.03 & 0.05 \\
\hline BodyL & -0.10 & -0.01 & -0.14 & -0.14 & 0.03 & -0.03 & 0.04 & 0.03 & 0.16 & 0.15 \\
\hline BackL & -0.06 & 0.15 & 0.12 & -0.14 & -0.01 & 0.00 & -0.05 & 0.21 & 0.04 & 0.28 \\
\hline Chestgirth & 0.07 & 0.16 & 0.07 & -0.10 & 0.08 & -0.00 & -0.60 & 0.42 & 0.05 & 0.06 \\
\hline Sscapula & 0.17 & 0.06 & 0.00 & 0.09 & 0.27 & 0.20 & 0.28 & -0.11 & 0.31 & 0.00 \\
\hline Sback & 0.19 & 0.11 & 0.12 & 0.06 & 0.01 & 0.01 & -0.07 & -0.07 & -0.22 & -0.28 \\
\hline Sflank & -0.02 & 0.02 & 0.00 & 0.03 & -0.06 & 0.01 & -0.02 & 0.19 & -0.18 & 0.04 \\
\hline Tscapula & 0.16 & -0.02 & 0.05 & $0.38^{*}$ & -0.25 & 0.03 & 0.27 & 0.02 & -0.02 & 0.04 \\
\hline Sback & -0.17 & -0.12 & -0.16 & -0.32 & $-0.41^{*}$ & -0.29 & $-0.44^{*}$ & -0.30 & -0.21 & -0.27 \\
\hline Tflank & 0.25 & 0.09 & 0.13 & 0.14 & 0.14 & 0.07 & 0.05 & -0.15 & 0.00 & -0.29 \\
\hline CountHair & -0.06 & -0.12 & -0.07 & 0.05 & -0.07 & 0.14 & 0.00 & 0.18 & 0.13 & 0.04 \\
\hline LengthHair & $0.46^{* *}$ & 0.27 & 0.31 & $0.38^{* *}$ & $0.42 * *$ & 0.15 & 0.26 & -0.05 & -0.007 & 0.10 \\
\hline \multicolumn{11}{|l|}{ H100 } \\
\hline Withers & -0.11 & 0.07 & -0.03 & -0.02 & -0.01 & 0.08 & 0.02 & 0.08 & 0.19 & 0.10 \\
\hline BodyL & 0.21 & 0.19 & 0.06 & 0.17 & 0.13 & -0.07 & 0.17 & -0.04 & -0.06 & 0.15 \\
\hline BackL & -0.17 & -0.05 & -0.08 & -0.07 & -0.10 & -0.12 & 0.06 & 0.20 & 0.26 & 0.08 \\
\hline Chestgirth & -0.05 & 0.09 & -0.00 & -0.21 & -0.28 & $-0.31 *$ & -0.00 & -0.09 & 0.00 & -0.03 \\
\hline Sscapula & -0.09 & 0.03 & 0.02 & 0.24 & 0.08 & 0.10 & 0.14 & 0.15 & 0.06 & 0.04 \\
\hline Sback & 0.07 & 0.04 & 0.19 & -0.09 & -0.08 & $-0.31^{*}$ & -0.15 & $-0.33^{*}$ & 0.24 & -0.16 \\
\hline Sflank & -0.02 & -0.13 & 0.04 & -0.12 & -0.14 & -0.16 & -0.03 & 0.08 & 0.12 & -0.08 \\
\hline Tscapula & 0.23 & 0.15 & -0.13 & 0.24 & 0.32 & 0.07 & -0.00 & 0.00 & -0.07 & 0.11 \\
\hline Sback & 0.06 & 0.02 & 0.15 & 0.11 & -0.15 & -0.03 & 0.06 & 0.16 & 0.06 & 0.08 \\
\hline Tflank & 0.03 & -0.17 & 0.02 & -0.27 & 0.22 & $-0.30^{*}$ & -0.13 & -0.23 & -0.12 & -0.16 \\
\hline CountHair & 0.07 & 0.21 & -0.17 & -0.04 & -0.12 & -0.06 & -0.23 & $-0.31^{*}$ & $-0.31^{*}$ & -0.23 \\
\hline LengthHair & -0.03 & 0.02 & 0.04 & $0.34 * *$ & 0.08 & 0.04 & -0.00 & 0.12 & 0.11 & 0.11 \\
\hline
\end{tabular}

Withers height at the withers, BodyL length of the body, BackL back length, Chestgirth chest girth, Sscapula skin thickness of the scapula, Sback skin thickness of the back, Sflank skin thickness of the flank, Tscapula thickness of the scapula, Tback thickness of the back, Tflank thickness of the flank, CountHair the hair count, LenghtHair length of hair, Eye eye, LeftS left side, RightS right side, LatUdder lateral udder, PostUdder posterior udder, Paw paw, $R T$ rectal temperature, $R R$ respiratory rate, $H R$ heart rate, $P S$ panting score

$* P<0.05 ; * *<<0.01$

crossbred animals, but with lower magnitude when compared to purebreds.

The principal factor analysis carried out with parameters measured in the morning (Fig. 2a) and physical characteristics showed that thermographic parameters and temperatures measured with the thermograph explain $38 \%$ of the total variation among these traits. The first principal factor was associated with physical characteristics (BackL, Chestgirth, Tback, and 
Table 5 Discriminant analysis of the physical characteristics of different genetic groups (GH50, GH75, and H100)

\begin{tabular}{lllll}
\hline Order & Variable & $R^{2}$ & Pr $>$ F & Pr $>$ AMCC \\
\hline 1 & Chestgirth & 0.997 & $<0.0001$ & $<0.0001$ \\
2 & Withers & 0.224 & $<0.0001$ & $<0.0001$ \\
3 & Sflank & 0.15 & 0.0002 & $<0.0001$ \\
4 & Sscapula & 0.13 & 0.0007 & $<0.0001$ \\
5 & BodyL & 0.065 & 0.0305 & $<0.0001$ \\
6 & CountHair & 0.086 & 0.0001 & $<0.0001$ \\
7 & LengthHair & 0.065 & 0.0317 & $<0.0001$ \\
\hline
\end{tabular}

Chestgirth chest girth, Wither withers, Sback skin thickness of the back, Sflank skin thickness of the flank, BodyL body length, CountHair the hair count, LenghtHair length of hair

BodyL), physiological parameters (RT and RR), and LatUdder temperature, and these measures vary according to the genetic group. The second factor was mainly associated with physical characteristics (Sflank, Sback, and Tflank).

In the afternoon (Fig. 2b), the first two principal factors explained $48 \%$ of the total variation. The first principal factor was related to physiological parameters, thermographic measurements (LatUdder and PostUdder), and physical characteristics (BackL, Chestgirth, withers). There were higher weights for Chestgirth, withers, LatUdder, PostUdder variables, and physiological parameters. The second principal factor was associated with physical characteristics (Sback, Tflank, Sscapula, CountHair) and the thermographic measurement RightS. Genetic group may explain the variation in thermographic and physiological measures. In general, the percentage of variance explained was low, but it was higher in the afternoon than in the morning.

\section{Discussion}

Before any considerations on our results, it is important to emphasize that cows used to belong to Embrapa and were not selected by the researchers. As already stated, our methodology involved heat stress induction, so, not to compromise milk production in the rest of the lactation, researchers only had access to a reduced number of animals, most of them in the final third of lactation (especially in the case of Holstein cows).

The Holsteins cows had higher averages for all physiological parameters, showing that these animals suffered more from heat stress compared to Girolando animals. To reduce heat stress, cattle use physiological adaptive mechanisms to lose heat, avoiding hyperthermia. Thus, increased respiratory rate and sweating are both important means of heat loss by evaporation (Baccari Jr. 2001). In this sense, rectal temperature and respiratory rate are considered the best physiological parameters to estimate the heat tolerance of cattle (McManus et al. 2009; Morais et al. 2008). In fact, the first visible physiological parameter that shows that animals are stressed is a change in RR (Vilela et al. 2013), and subsequently an increase in RT occurs. The reference ideal values for rectal temperature may vary from 38.0 to $39.3{ }^{\circ} \mathrm{C}$ for dairy cows (Du Preez 2000) and ideal respiratory frequency around 40
Fig. 1 Canonical analysis of physical characteristics in different genetic groups of dairy cows. Withers height at the withers, BodyL length of the body, BackL back length, Chestgirth chest girth, Sscapula skin thickness of the scapula, Sback skin thickness of the back, Sflank skin thickness of the flank, Tscapula thickness of the scapula, Tback thickness of the back, Tflank thickness of the flank, CountHair the hair count, LenghtHair length of hair

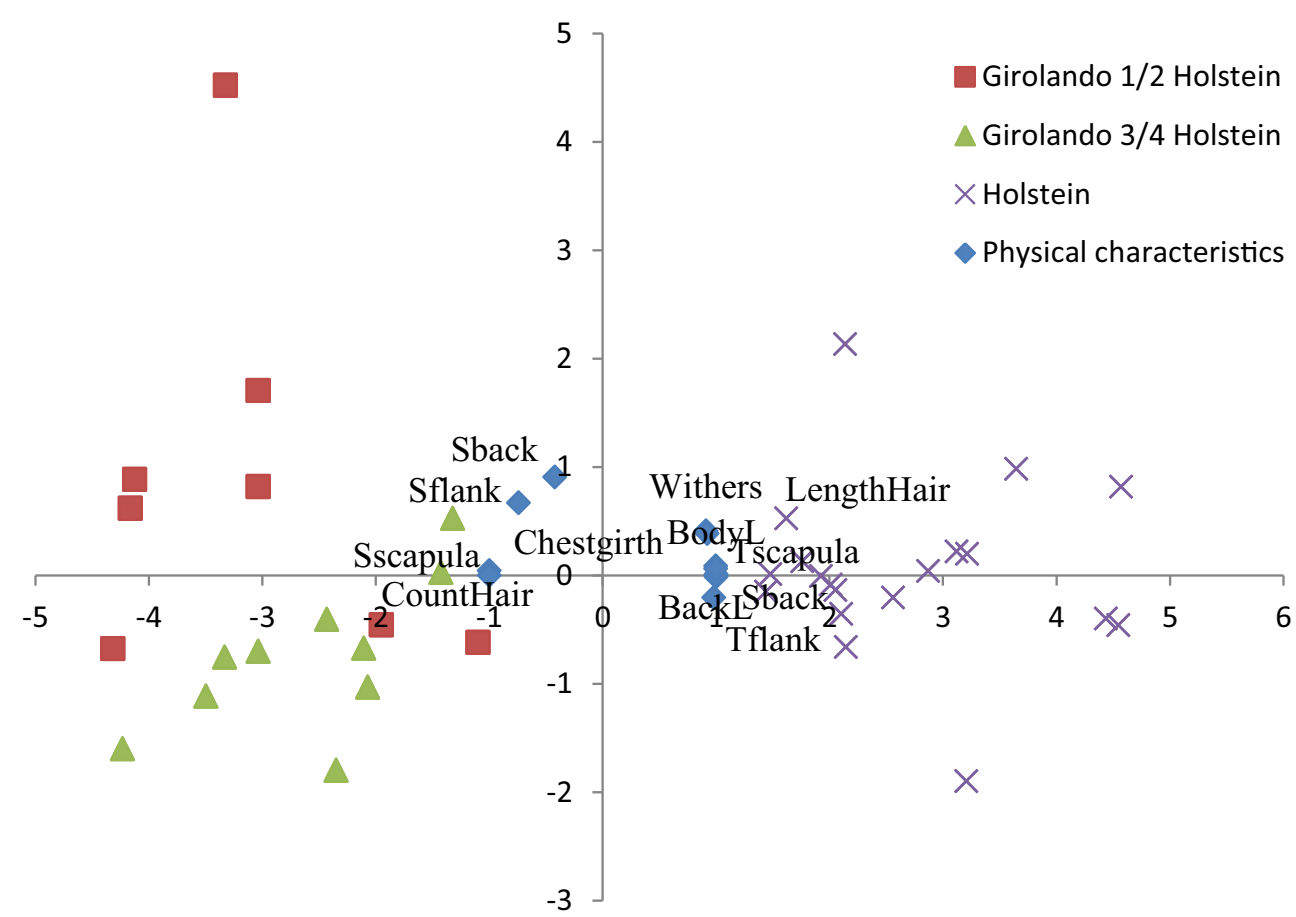


Fig. 2 Orthogonal plan of the principal factors for physical and physiological parameters as well as infrared temperatures in different genetic groups of dairy cattle during the morning (a) and afternoon (b). Withers height at the withers, BodyL length of the body, BackL back length, Chestgirth chest girth, Sscapula skin thickness of the scapula, Sback skin thickness of the back, Sflank skin thickness of the flank, Tscapula thickness of the scapula, Tback thickness of the back, Tflank thickness of the flank, CountHair the hair count, LenghtHair length of hair, Eye eye, LeftS left side, RightS right side, LatUdder lateral udder, PostUdder posterior udder, Paw paw, $R T$ rectal temperature, $R R$ respiratory rate, $H R$ heart rate, $P S$ panting score
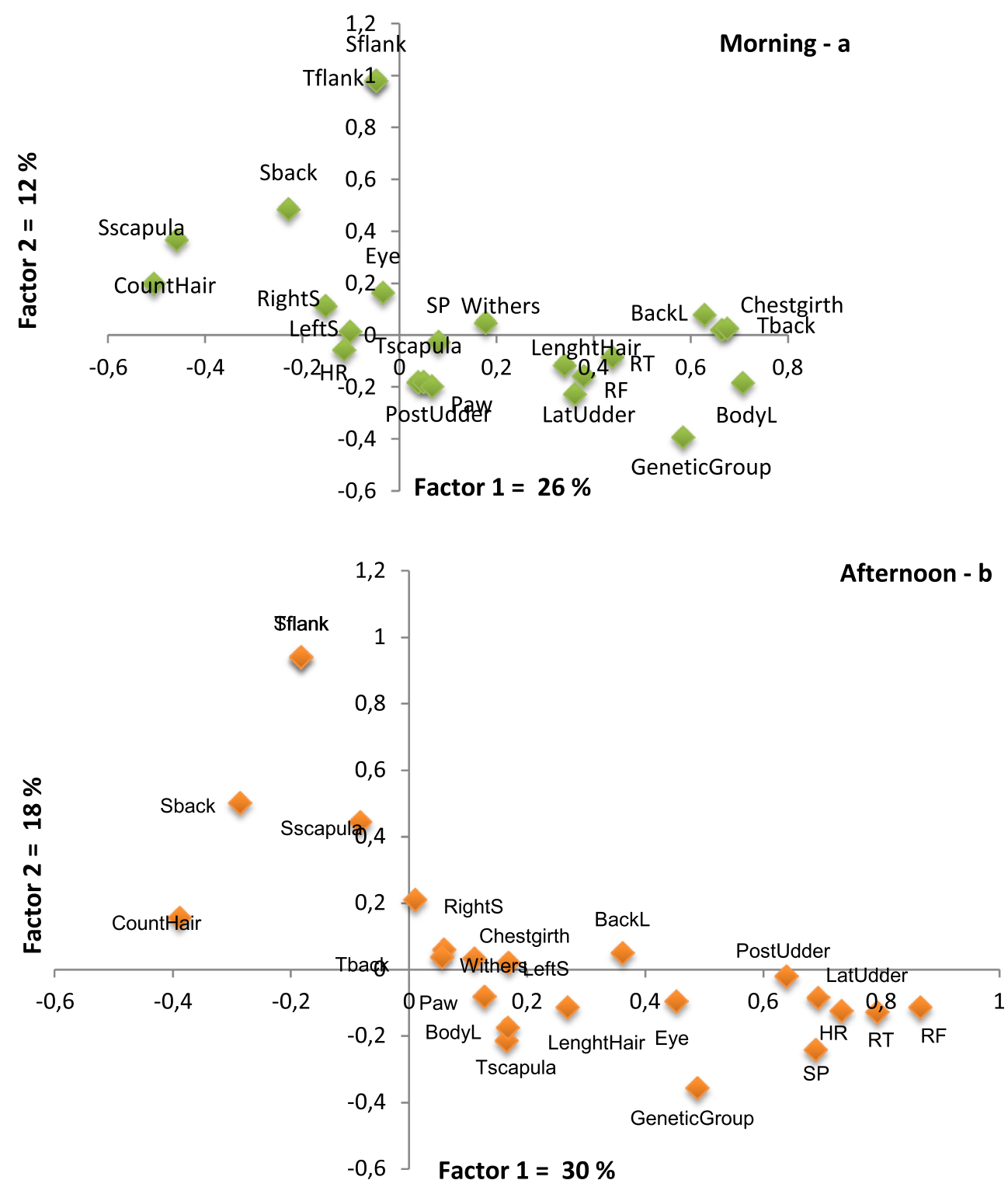

60 breaths/min (Silanikove 2000). In the afternoon, animals of all genetic groups were under heat stress.

Purebreds are less adapted to climate change, since they have more problems in losing heat, while smaller animals such as Girolando (GH50 and GH75) have greater ease (McManus et al. 2009). The genetic group influenced body measurements. Holstein cows were larger than Girolando cows (GH50 and GH75). Bianchini et al. (2006) found results similar to this experiment, in which Holstein cows also showed higher means for body measurement than other cattle breeds studied. Fitzhugh (1978) stated that a smaller body size may have important biological advantages and aspects related to adaptation and resistance. However, it is difficult to establish the ideal size of an animal for all situations. The larger animals show hindered heat dissipation and retain heat longer than smaller animals due to a greater body area exposed to sunlight (Souza Junior et al. 2008). This is confirmed in the principal component analysis in the afternoon, where the animals with the largest body measurements are those with both an increase in respiratory and heart rates.

Besides being larger animals, Holstein cows also had thicker coats, which hinder heat loss. Holmes (1985) suggests that animals with thicker and denser coats have more difficulty in eliminating latent heat via cutaneous evaporation. Although the number of hairs per square centimeter was lower in the Holstein, hair length was greater, making it difficult to lose heat by evaporation of moisture on the skin surface, which forced these animals to use other resources to lose heat.

Multiple regression equations and their correlation coefficients among the physical, physiological, and infrared measurements taken in the afternoon were generated to determine which variables would be the best predictors in the evaluation 
of heat stress. Although significant regression equations were found, the $R^{2}$ values were lower than $5 \%$, so little variation can be explained. These regressions are important because they allow the construction of models considering the correlation structure among the studied physical characteristics. Thus, results have showed that the physical characteristics are not useful in predicting heat tolerance in the genetic groups investigated in this study.

GH75 cattle presented moderate positive correlation with the body length and temperatures of the Eye, LatUdder, and PostUdder in the afternoon. This may be due to the protective properties of the animals that depend on morphological characteristics, allowing the animal to effectively exchange heat with the environment through radiation, conduction, convection, and evaporation (Silva et al. 2006), which confirms that these animals were able to eliminate heat more easily, thereby being less stressed than Holstein cattle.

The correlations were negative, but significant, between the number of hairs and physiological parameters in Holstein cows. This demonstrates that an increase in RR and HR is expected in this breed when the number of hairs is lower.

The low number of hairs found in the present experiment may be due to the time when this experiment was developed (summer). Hair molts from winter to summer, and the time of year impacts on its physical characteristics (Pinheiro and Silva 2000).

McManus et al. (2011), in a study evaluating heat tolerance in cattle, corroborate the results of this work, in which the discriminant analysis also showed height and chest girth as variables that most influence heat tolerance. The exotic H100 animals exhibited morphological and physiological characteristics that led to poorer adaptation to the tropical environment, thus being different from Girolando (GH50 and GH75). In the same analysis, the second axis showed that on average, Girolando animals grouped together, suggesting that they are better adapted to the tropical climate (Facó et al. 2005).

\section{Conclusion}

The Holstein cattle were less tolerant to heat stress than Girolando (GH50 and GH75) as these animals had more difficulties in dissipating heat due to their larger body size, as well as thicker and longer hair.

The correlations between physical and physiological and thermographic measures were inconsistent between genetic groups and are therefore not predictive of heat tolerance, while regressions of morphometric characteristics on physiological and thermographic were not significant.

Thus, physical characteristics were not good at predicting physiological responses and thermographic temperatures in dairy cattle and therefore should not be used.
Acknowledgments Thanks are due to CNPq and INCT-Pecuária (MCT/CNPq/FAPEMIG) for financing.

Conflict of interest The authors declare that they have no competing interests.

\section{References}

Baccari Junior F (2001) Manejo ambiental de vaca leiteira em climas quente. Uel, Londrina, p 142

Bianchini E et al (2006) Características corporais associadas com a adaptação ao calor em bovinos naturalizados brasileiros. Pesqui Agropecuária Brasileira, Rio de Janeiro 41:1443-1448

Dikmen S, Hansen PJ (2009) Is the temperature-humidity index the best indicator of heat stress in lactating dairy cows in a subtropical environment? J Dairy Sci Champaign 92:109-116

Du Preez JH (2000) Parameters for the determination and evaluation of heat stress in dairy cattle in South Africa. J Vet Res 67:263-271

Façanha DAE et al (2013) Tendências metodológicas para avaliação da adaptabilidade ao ambiente tropical. Revista Brasileira de Saúde e Produção Animal, Salvador 14:90-101

Façanha-Morais DAE et al (2008) Variação anual de hormônios tireoidianos e características termorreguladoras de vacas leiteiras em ambiente quente. Revista Brasileira de Zootecnia, Viçosa 37 : 538-545

Faco O et al (2005) Idade ao primeiro parto e intervalo de patos de cinco grupos genéticos Holandês X Gir no Brasil. Revista Brasileira de Zootecnia 34:1920-1926

Fitzhugh HA (1978) Animal size and efficiency, with special reference to the breeding female. Anim Prod 27:393-401

Gebremedhin KG, Wu B (2002) Simulation of sensible and latent heat losses from wet-skin surface and fur layer. J Therm Biol 27:291-297

Holmes CW (1985) A note on the protection provided by the hair coat or fleece of the animal against the thermal effects of simulated rain. Animal Production 32:225-226

Lima IA et al (2013) Thermoregulation of Girolando cows during summertime, in Pernambuco State, Brazil. ActaScientarium, Maringá 35:193-199

Mader TL, Davis MS, Brown-Brandl T (2006) Environmental factors influencing heat stress in feedlot cattle. J Animal Sci Champaign $84: 712-719$

Marai IFM, El-Darawany AA, Fadiel A et al (2007) Physiological traits as affected by heat stress in sheep — a review. Small Rumin Res 71: $1-12$

Martins RFS, Paim TP, Cardoso CA et al (2013) Mastitis detection in sheep by infrared thermography. Res Vet Sci Res Vet Sci 94 : $722-724$

McManus CM et al (2009) Heat tolerance in naturalized Brazilian sheep: physiological and blood parameters. Trop Anim Health Prod 41:95-101

McManus CM et al (2011) Use of multivariate analyses for determination of heat tolerance in Brazilian cattle. Trop Animal Health Prod 43: 623-630

Montanholi YR et al (2008) Application of infrared thermography as an indicator of heat and methane production and its use in the study of skin temperature in response to physiological events in dairy cattle (Bos taurus). J Ther Biol 33:468-475

Morais DAEF et al (2008) Variação anual de hormônios tireoideanos e características termorreguladoras de vacas leiteiras em ambiente quente. RevistaBrasileira de Zootecnia 37:538-545

Nascimento GVD et al (2013) Indicadores produtivos, fisiológicos e comportamentais de vacas de leite. Agropecuária Científica no Semiarido 9:28-36 
Paim TP et al (2013) Thermographic evaluation of climatic conditions on lambs from different genetic groups. Int J Biometeorol 57:59-66

Perissinotto $\mathrm{M}$ et al (2009) Conforto térmico de bovinos leiteiros confinados em clima subtropical e mediterrâneo pela análise de parâmetros fisiológicos utilizando a teoria dos conjuntos fuzzy. Ciência Rural Santa Maria 39:1492-1498

Pinheiro MG, Silva RG (2000) Estação do ano e características do pelame de vacas da raça Holandesa. B Ind Animal Nova Odessa 57:99-103

Rodrigues AL et al (2010) Influëncia do sombreamento e dos sistemas de resfriamento no conforto térmico de vacas leiteiras. Agropecuária Científica no Semi-Árido 6:14-22

Schaefer AL, Cook NJ, Church JS, Basarab J, Perry B, Miller C, Tong AK (2007) The use of infrared thermography as an early indicator of bovine respiratory disease complex in calves. Res Vet Sci 83: 376-384

Silanikove N (2000) Effects of heat stress on the welfare of extensively managed domestic ruminants. Livest Prod Sci 67:1-18, Beit Dagan

Silva GDA et al (2006) Effect of year time and period of day on physiological parameters of reproductive goats in the semi-arid Paraiba. Revista Brasileira de Engenharia Agrícola e Ambiental 10:903-909
Silva IJO et al (2002) Efeitos da climatização do curral de espera na produção de leite de vacas holandesas. Revista Brasileira de Zootecnia 31:2036-2042

Silva RG (1999) Estimativa do balanço térmico por radiação em vacas Holandesas expostas ao sol e à sombra em ambiente tropical. Revista Brasileira de Zootecnia 6:1403-1411

Silva RG (2000) Introdução a bioclimatologia animal. Nobel, São Paulo, p 286

Souza Junior S et al (2008) Características termorreguladoras de caprinos, ovinos e bovinos em diferentes épocas do ano em região semiárida. Revista Científica de Produção Animal 10:127-137

Stewart M, Stafford KJ, Dowling SK, Schaefer AL, Webster E Jr (2008) Eye temperature and heart rate variability of calves disbudded with or without local anaesthetic. Physiol Behav 93:789-797

Tosetto MR et al (2014) Influência do macroclima e do microclima sobre o conforto térmico de vacas leiteiras. J Animal Behav Biometereol Palmeira das Missões 2:6-10

Vilela R et al (2013) Respostas fisiológicas e comportamentais de vacas holandesas mantidas em sistema adiabático evaporativo. Pesqui Vet Bras 33:1379-1384

$\mathrm{Xu} \mathrm{F}$ et al (2007) Biothermomechanics of skin tissues. J Mech Phys Solids 56:1852-1884 